\title{
A Pós-Graduação em História: novas e velhas Questões*
}

Sílvia Regina Ferraz Petersen**

É justo que dediquemos algum tempo para brindar, como se diz na linguagem dos historiadores, a "experiência da duração" do nosso Programa de Pós-Graduação em História, pois duas décadas constituem um marco suficientemente amplo para merecer algum tipo comemoração. Não falta conteúdo simbólico à data, quando vemos que a atual Coordenadora do Programa, Professora Cláudia Wasserman, há exatos 20 anos acabava de ser aprovada na seleção para a primeira turma do então Curso de Mestrado. E eu, que fazia parte daquela comissão examinadora, hoje sou distinguida com o convite para falar nessa oportunidade aos colegas e estudantes!

Não é fácil estabelecer o conteúdo e a forma de uma exposição - que deve ser breve e sem apologias - para marcar o $20^{\circ}$

\footnotetext{
* Este texto mantém a versão que foi apresentada oralmente em abril de 2006.

** Professora do Departamento e do PPG em História da UFRGS.
} 
A Pós-Graduação em História...

aniversário do nosso PPG. Então pensei que, através desta proposta de percorrer "novas e velhas questões", seria possível examinar alguns temas importantes para professores e estudantes que se preocupam em pensar a Pós-Graduação em História - a nossa inclusive - tendo por horizonte um compromisso claro com a qualidade do ensino e da pesquisa, com o aperfeiçoamento da formação profissional do historiador e com um padrão de convivência acadêmica que propicie condições para isso.

A exposição que vou fazer expressa meu ponto de vista, mas, de qualquer forma, não é apenas "impressionista". Ela resulta da experiência que acumulei como docente, orientadora, coordenadora e representante da Pós-Graduação em História junto ao Conselho Nacional de Pesquisa (CNPq) e à Coordenação de Aperfeiçoamento de Pessoal de Nível Superior (CAPES) o que, afinal, não é uma trajetória insignificante para constituir o lugar de onde falo.

Já que o tempo é limitado, optei por discutir dois temas que me parecem importantes e abrangentes:

1) a área de concentração e as linhas de pesquisa;

2) o corpo discente.

Mas, antes de tratar deles, desejo fazer um comentário preliminar sobre o reconhecimento acadêmico que o Departamento e o PPG em História hoje possuem em nossa Universidade. Só para lembrar, o Departamento ocupava em 2004 (ano da última lista comparativa a que tive acesso) o segundo lugar dentre todos os cursos de Graduação em História submetidos ao Exame Nacional de Cursos, só abaixo da Universidade Federal do Rio de Janeiro (com 58,5 pontos numa média de 50,3 dos dez melhores do ranking). O PPG, na última avaliação trienal da CAPES (2004), obteve nota cinco em um máximo de sete pontos, só superada por outros quatro programas: Universidade Federal Fluminense (UFF), Universidade de São Paulo (USP)/História Social, Universidade Estadual de Campinas (UNICAMP) e Universidade Federal do Rio 
Janeiro (UFRJ), num conjunto de 34 programas, sendo 29 então avaliados (a lista da CAPES, em todo o caso, hoje já revela a existência de 40). Sem entrar em outros indicadores de qualidade, esses certamente nos colocam em uma posição de muito destaque dentre os cursos que a Universidade Federal do Rio Grande do Sul (UFRGS) oferece.

Embora o Departamento de História, desde sua criação, sempre gozasse de prestígio junto aos pares e à comunidade, o reconhecimento da importância e da qualidade de seu trabalho dentro da Universidade nem sempre foi assim e a distância temporal não é tão grande para que eu esqueça como era tratado o grupo de professores do Departamento, do qual eu fazia parte, que lutava para dar início ao Mestrado e não conseguia sequer ingressar no gabinete do pró-reitor, tal o descaso com que a História era vista na Universidade dos anos 1980. Hoje parece inacreditável que tenhamos conseguido criar o Mestrado de acordo com um projeto que foi resultado de nossa experiência em cursos de especialização desde 1977, pois, nos primeiros anos, estávamos ao sabor da pressão de sucessivas comissões de avaliação da CAPES e da própria pró-reitoria que, sem consideração por nosso trabalho, ditavam, cada qual por seu lado, sugestões que devíamos incorporar independente de que tivessem qualquer identidade com nosso projeto e sob pena de não obtermos o necessário reconhecimento institucional. Quantas vezes o projeto teve que ser reformulado para incorporar o que não era incorporável, não por inconsistência da proposta, mas por um simples exercício de poder sobre um conhecimento "pouco importante" para uns, na UFRGS, e para outros, no caso das comissões da CAPES, sobre um curso considerado uma espécie de "soluço" ou "extra-sístole" regional, que escapava do eixo acadêmico dominante. Mas apesar de tudo, o projeto foi aprovado, o que depõe a favor de sua qualidade original. Talvez não por acaso, acabei me integrando na linha de pesquisa "Relações Sociais de Dominação e Resistência"... 
A Pós-Graduação em História...

Mas isso é passado e o Programa consolidou-se apesar de dificuldades que pareciam intransponíveis. Já há muitos anos, o Departamento e a Pós-Graduação em História possuem uma justa posição de reconhecimento e prestígio em nossa Universidade e nas Agências de Avaliação e Fomento as quais também, felizmente, experimentaram profundas transformações no sentido da democratização de suas gestões e da inegável qualificação de seus quadros.

Quis começar o texto com esse tema pois, para os estudantes e muitos dos colegas que hoje integram o nosso Programa, este é um passado desconhecido, mas que precisa ser lembrado como ponto de referência para que se possa avaliar onde hoje nos encontramos. Olhando para trás, podemos concluir que estamos em uma posição academicamente confortável, mas se desejamos faz̧er diferença no conjunto da pós-graduação e, principalmente, na produção historiográfica brasileira, acho que ainda temos muito, muito trabalho pela frente. Os temas que vou tratar têm a ver com isso.

Quando se examinam questões de fundo para o aperfeiçoamento de um PPG em História, no sentido de formar historiadores cada vez mais qualificados, há que considerar sempre a existência de um marco muito complexo, no interior do qual qualquer análise tem que ser colocada. Este marco é constituído por duas referências permanentes:

1) a necessidade de criar um mínimo de unidade - por exemplo, os próprios objetivos acadêmicos do Programa - a partir da diversidade inerente à composição do seu corpo docente;

2) a necessidade de acolher ou enfrentar as diretrizes sempre cambiantes da política das agências de fomento.

Vou detalhar um pouco essas duas referências pois, mesmo em medidas diferentes, elas são comuns a todos os Programas e incidem no leque de possibilidades de suas transformações mais profundas. 
No primeiro caso, qualquer PPG tem em sua base uma "cultura acadêmica". Cultura esta construída basicamente pelos docentes e que se nutre, entre outros, dos seguintes elementos: diferentes concepções sobre o conhecimento histórico e a pós-graduação, diferentes trajetórias acadêmicas dos professores e orientadores, dedicação sistemática ao aprimoramento do programa e individualismo incapaz de qualquer esforço coletivo, padrões excelentes e padrões medíocres e até antiéticos de desempenho da docência e orientação, visão acadêmica e visão burocrática de gestão, etc.

No segundo caso, ou seja, a necessidade ora de acolher, ora de enfrentar as diretrizes das agências de fomento, refiro-me ao seguinte: se, por um lado, a CAPES e o CNPq possuem, pelas legítimas e continuadas funções de avaliação que desempenham, uma visão de conjunto dos Programas (o que tecnicamente lhes permite definir critérios para a "saúde acadêmica" dos mesmos), por outro e pelo mesmo caminho da generalização, é freqüente que diluam diferenças entre as áreas, criando um "tipo ideal" de Programa que perde de vista exatamente esta complexidade interna que eles possuem; que alterem radicalmente critérios de avaliação que muitas vezes tinham custado enormes esforços de adequação por parte dos Programas ou ainda que não percebam a própria descontinuidade ou contradição das recomendações ou exigências feitas entre uma avaliação e outra de um mesmo Programa. Não podemos esquecer que essas agências são as que formulam e executam a política de distribuição de bolsas e demais recursos de manutenção dos cursos, sem os quais eles não poderiam cumprir suas finalidades acadêmicas.

Se nos colocamos numa perspectiva de tempo, foi um ganho inegável a possibilidade dos Programas indicarem candidatos a seus representantes tanto na CAPES como no $\mathrm{CNPq}$, o que não significa que eles sejam automaticamente conduzidos ou que possam transformar as políticas das próprias agências. Nesse sentido, 
A Pós-Graduação em História...

também significou um salto qualitativo a criação do Fórum dos Coordenadores da PG em História, promovido pela Associação Nacional de História (ANPUH), cuja finalidade é exatamente pensar coletiva e criticamente esses cursos, embora essa reflexão esbarre nos mesmos limites a que me referi antes.

Enfim, quando tratar das questões seguintes, não quero que se perca de vista esta dupla e complexa determinação dos PPGs em História: sua "cultura acadêmica" e o peso das agências de fomento. Começarei abordando a sempre discutida e nunca concluída definição da "área de concentração" e das "linhas de pesquisa".

Muitos Programas, quando foram criados, não estabeleceram uma área de concentração, mesmo porque este sempre foi um conceito pouco claro. Mas, a partir de um determinado momento na década de 1990, os formulários dos relatórios para a CAPES, por razões que desconheço, criaram um campo de preenchimento onde devia ser indicada uma área de concentração, mesmo que o curso não a tivesse. Ou seja, o mundo virtual exige e o mundo real cria, numa inversão que honra a condição pós-moderna... Dessa forma, vários cursos - o nosso inclusive - fizeram o que era mais lógico e razoável como solução a posteriori: indicaram como área de concentração a História Social, por razões que não é necessário explicar para um público de historiadores. Afinal, em seus Combates pela História Lucien Febvre já escrevia que "a História é inteiramente social, por definição". Assim, adotar a História Social como área de concentração significa desenvolver procedimentos interpretativos que possibilitem estudar as formas pelas quais os sujeitos históricos constituem seus modos de viver, considerando todo o conjunto de práticas sociais vinculadas às estruturas e experiências históricas. Enfim, é um bom ponto de partida. Além disso, no nosso caso, essa área dava abrigo às nossas linhas de pesquisa, que devem ser o coração de um Programa. 
Não quero dizer com isso que seja desnecessária a explicitação de uma área ou interesse central que sirva de sinalizador das linhas de pesquisa. Linhas que, por sua vez, são os troncos de onde devem derivar as disciplinas e produção científica de um Programa. Mas não é fácil definir o que é uma área de concentração e, para tanto, basta observar o que isso significa em certos casos. Vejamos apenas o exemplo de nossos vizinhos: a Universidade do Vale do Rio dos Sinos (UNISINOS) tem como área de concentração os Estudos Históricos Latino-Americanos e a Pontifícia Universidade Católica do Rio Grande do Sul (PUCRS), que até 1993 tinha três áreas (História do Brasil, História Ibero-Americana e Arqueologia), agora se concentra em História das Sociedades IberoAmericanas.

Se "área de concentração" é uma designação tão ampla que em geral não chega a produzir efeitos importantes na estrutura curricular, outro caso é o das "linhas de pesquisa". As linhas de pesquisa, seu conceito, seu conteúdo, sua relação com a estrutura de ensino e pesquisa de um Programa, com suas teses e dissertações e até mesmo a coerência que cada vez mais se procura entre as linhas e a produção científica de professores e estudantes, deveriam ser temas permanentes quando se trata de pensar academicamente um PPG em História.

Geralmente, quando um Programa é criado, as linhas derivam das investigações concretas que os docentes estão realizando e que significam sua experiência de pesquisa. Constituem-se na medida em que algumas dessas pesquisas podem ser agrupadas com uma certa unidade que faça sentido temático e teórico. Mas, em relação às linhas de pesquisa, não podemos perder de vista pelo menos o seguinte: a constituição de grupos de pesquisa, que sustentem efetivamente uma linha, é uma prática que exige vontade acadêmica, que requer de cada docente abrir mão de uma parte de seus interesses pessoais, pensando em constituir ou consolidar a identidade da linha, pensando em oferecer resultados de pesquisa 
A Pós-Graduação em História...

e reflexão historiográfica que possam ter significado nas próprias discussões nacionais sobre um campo do conhecimento histórico, pensando também em poder apresentar projetos coletivos de pesquisa às agências de fomento, através dos quais, além de conhecimento histórico, se obtenha recursos para adquirir equipamentos, livros, trazer convidados, integrar bolsistas, etc. No entanto, o que se verifica freqüentemente é a permanência da forte tradição de pesquisas individuais (que muitas vezes decorrem do próprio tema da tese de doutorado do docente) o que, se é legítimo, não consegue avançar no sentido do que comentei acima.

Via de regra, as linhas surgem porque um tema similar está sendo pesquisado em diferentes projetos e não devido a uma proposta coletiva. Por isso, as linhas funcionam mais como "frentes" onde se tenta reunir algumas pesquisas que, na verdade, não resultam de um investimento coletivo em uma temática e problemática, de uma relação concreta interpesquisas, mas de um agrupamento ligado por elos muito frágeis, em geral ocasionais, casuais e imprecisos. Acho que em vez de linhas, nossos Programas em geral trabalham com "listas" de projetos.

Essa imprecisão e fragilidade no traçado das linhas têm produzido o efeito de que praticamente tudo possa ser colocado como objeto de dissertação ou tese, ou no caso dos relatórios para a CAPES, como "produção científica da linha", atomizando as investigações de docentes e estudantes, dispersando o que deveria ser efetivamente um esforço centrado em algumas problemáticas consideradas relevantes para os objetivos do Programa, enfim, diluindo a identidade das próprias linhas.

É inegável que a criação e consolidação dos Grupos de Trabalho da ANPUH, que fazem reuniões periódicas e organizam muitos simpósios temáticos, têm contribuído para uma menor fragmentação nas atividades de pesquisa e para colocar em efetivo diálogo os pesquisadores. Também não se pode desconhecer o estímulo por parte das agências de fomento a projetos integrados, 
que promovem investimentos coletivos mais sólidos e são uma insubstituível via de acesso a recursos sempre escassos para a pesquisa em Ciências Humanas.

Mas, remetendo àqueles parâmetros antes expostos, que marcam a existência dos Programas e dentro dos quais também a questão das linhas de pesquisa tem que ser colocada, podemos ponderar que a aprovação de um projeto integrado exige, entre outros requisitos das agências, a demonstração de experiência prévia dos proponentes e que o projeto não seja apenas uma colagem de temas tornados discursivamente "afins". Ainda deve-se considerar que concorrer a tais financiamentos significa muitas vezes que um grupo de pesquisadores tenha de abrir mão ou fazer desvios consideráveis nos objetivos originais de seus projetos para encontrar um denominador comum capaz de preencher as exigências desta ou daquela agência financiadora. Tais observações servem para mostrar que essa importante via de estímulo ao trabalho coletivo ainda é muito tímida para produzir efeitos mais visíveis na consolidação de linhas de pesquisa nos PPGs.

Não é fácil também, em nossa cultura acadêmica, reunir professores (com diferentes interesses, perspectivas teóricas e trajetórias de pesquisa às vezes já consolidadas) em efetivas linhas de pesquisa, até pela dificuldade de estabelecer um entendimento comum sobre o que é uma linha de pesquisa. A isso se agrega a referida tradição da pesquisa individual, o desinteresse em construir alguns trabalhos conjuntos, com as dificuldades que lhes são próprias, quando o principal parece ser pilotar bem a própria carreira. Essa miopia quanto aos interesses coletivos de um determinado Programa - eu diria mesmo falta de visão estratégica sobre sen futuro - também se observa em relação à dificuldade de estimular, como parte da política acadêmica dos mesmos, iniciativas referentes à abertura de novos campos de pesquisa, que muitas vezes definham por falta de apoio do próprio Programa, apesar de sua 
A Pós-Graduação em História...

potencialidade para alavancar a produção científica, teses, dissertações, etc.

Outra questão que incide na dificuldade de consolidação das linhas de pesquisa decorre da renovação do corpo docente, que é um processo extremamente saudável na vida dos PPGs, mas, como é normal, muitas vezes envolve profissionais que, por suas trajetórias de pesquisa, não necessariamente desejam ou podem se integrar nas linhas existentes. No entanto, nem sempre é possível criar uma nova linha, pois há um conjunto de requisitos acadêmicos e formais para isso e uma complicada estrutura curricular que não pode ser modificada a cada momento. Daí que muitos Programas acabem por inventar formas enviesadas ou artificiais para integrar o docente em uma das linhas, o que em nada contribui para sua satisfação profissional ou para a consolidação das mesmas.

É preciso ponderar também que, embora as agências tenham como referência uma espécie de "tipo ideal" da pós-graduação, onde tudo deveria funcionar como engrenagens bem azeitadas de um sistema, - e nesse caso os professores deveriam se integrar perfeitamente às linhas de um Programa -, na vida real isso não acontece e não deveria ser visto por elas como um "defeito sistêmico", mas como o processo natural em que conservação e transformação estão sempre coexistindo. O problema é que o Programa é avaliado por um grau de coerência, identidade e organicidade entre suas linhas de pesquisa, projetos, disciplinas, teses, dissertações, orientações de bolsistas, etc., que, se é certamente o horizonte desejável, não existe com esse funcionalismo imaginado. Além disso, na problemática das linhas de pesquisa, é preciso ainda agregar o expediente das "maquiagens discursivas", por meio das quais alguns Programas mais pragmáticos e menos escrupulosos renomeiam o mesmo sem que nada substancialmente mude, para apresentar, com mais ou menos sucesso, uma "versão" adequada às exigências da avaliação.

Anos 90, Porto Alegre, v. 13, n. 23/24, p.29-44, jan./dez. 2006 
Nessa questão das linhas, entendo que nada substitui a decisão consciente e coletiva de um Programa - que é uma decisão de política acadêmica - no sentido de constituir linhas com efetiva densidade temática e teórica. Quando falo em "Programa", entendase "corpo docente", porque os alunos, nesse particular, participam apenas sofrendo ou se beneficiando dos resultados das decisões, do empenho ou descaso dos docentes. Efetivamente, por maior que seja o esforço do corpo discente como um todo ou através de sua representação, trata-se de uma decisão e uma responsabilidade fundamentalmente do corpo docente e não pode ser transferida ou distribuída. Essa não é uma questão menor e os Programas que não conseguirem dar esse salto estarão destinados à mediocridade acadêmica. Linhas de pesquisa consistentes e bem definidas são a base para uma estrutura curricular clara e bem fundamentada, para dar às disciplinas, projetos e produção científica a identidade do Programa, a referência do que ele é para quem deseja uma determinada formação histórica.

Por tudo isso, não é exagero colocar a questão das linhas de pesquisa na pauta das prioridades quando se analisa criticamente a pós-graduação em História, quando se deseja fazer um processo de reflexão sistemática sobre sua própria produção para que ela possa ter uma mudança de qualidade. Concordo com o entendimento que existe nas avaliações e recomendações da CAPES em relação às linhas de pesquisa, de que sua finalidade é dar uma direção específica a um conjunto de pesquisas com significado para a área de concentração e que sejam do interesse do Programa. Desejável seria que cada linha se constituísse como uma unidade problemática que fosse referência aos projetos que venham a se desenvolver em seu interior, cada um deles capaz de produzir diferentes intervenções nessa problemática da linha, investigando desde as perspectivas teóricas e delimitações que interessassem ao pesquisador - docente ou discente - com diferentes cortes temáticos, espaciais e cronológicos, em âmbito de micro ou macro 
A Pós-Graduação em História...

análise, sob a forma de estudos de caso ou análises comparativas, etc.

Tudo isso talvez produzisse como resultado um adensamento da pesquisa e da produção científica do Programa, sua organicidade curricular e a possibilidade de perceber tanto os pontos frágeis e lacunas da pesquisa, como seus pontos fortes, servindo também de referência para os alunos escolherem os temas de suas teses e dissertações. Mas, com freqüência, é o contrário disso que ocorre: uma dispersão e pulverização do ensino e da pesquisa que pouco contribuem para a qualidade de Programas que, afinal, têm um enorme compromisso com o próprio perfil da historiografia que se produz no Brasil.

A segunda questão que desejo tratar nessa oportunidade diz respeito ao corpo discente dos PPGs em História e me refiro aqui especialmente ao mestrado. Candidatos cada vez mais jovens participam da seleção aos mestrados, muitos imediatamente após concluir a graduação. Acho que já é comum entre os estudantes considerar a pós-graduação como a continuidade necessária da graduação. Não é um estímulo menor a possibilidade de obter uma bolsa, o que resolve por algum tempo a complicada inserção no mercado de trabalho. Isso não é nenhuma crítica: é apenas uma constatação.

Mas o ingresso precoce tem seus efeitos: apesar de seleções cada vez mais exigentes (o que não significa necessariamente mais apropriadas para encontrar os melhores candidatos) e embora a apresentação de um projeto ou pré-projeto de pesquisa seja um importante instrumento de avaliação, isso não identifica automaticamente um aluno mais preparado ou maduro para enfrentar as exigências de cursos de pós-graduação com currículos pesados em créditos, conteúdos e monografias e a formidável pressão de produzir e defender uma dissertação em 24 meses caso tenha uma bolsa ou encontre um trabalho, o que reduz o tempo de dedicação ao curso.

Anos 90, Porto Alegre, v. 13, n. 23/24, p.29-44, jan./dez. 2006 
Esse quadro complica-se quando observamos que o conceito do que é uma dissertação ficou muito impreciso desde que a maioria dos cursos passou a oferecer mestrado e doutorado, sem delimitar com mais clareza o que diferencia as dissertações das teses. Não é de admirar que os Programas tenham dificuldade em enfrentar essa questão, quando o próprio parecer 977/ 65 (C.E.Su./ C.F.E) que definiu os cursos de pós-graduação era tão impreciso. Cito: "do candidato ao Mestrado exige-se dissertação, sobre a qual será examinado, em que revele domínio do tema escolhido e capacidade de sistematização; para o grau de Doutor, exige-se a defesa de tese que represente trabalho de pesquisa importando em real contribuição para o conhecimento do tema". Para não alongar a descrição de um fato que todos nós conhecemos, vou direto para duas de suas conseqüências mais visíveis:

1) uma grande disparidade dos resultados: alguns trabalhos de mestrado são verdadeiras teses e outros não se distinguem de uma monografia de graduação;

2) uma grande disparidade na avaliação dos trabalhos. Se nesse processo existe o imponderável dos componentes de uma banca, mais complicado torna-se quando não há marcos para balizar a atribuição das notas, conceitos ou pareceres. Para os que acompanham as defesas em um Programa, não é difícil constatar que às vezes dissertações com nota 10 ou " $\mathrm{A}$ " são constrangedoramente inferiores a outras, com nota 7 ou 8 ou "B".

Avaliações tão díspares produzem perplexidade e insegurança nos alunos pois, pela falta de referências mais precisas, acabam confusos quanto ao que deles é esperado, sobretudo naqueles Programas em que a dissertação é colocada praticamente como a única finalidade do curso. Assim, sem um enfrentamento deliberado dessa questão de forma coletiva pelo corpo docente e discente, a qualidade das dissertações de um Programa certamente fica comprometida e sujeita a imponderáveis oscilações entre excelência e 
A Pós-Graduação em História...

intranscendência, acumulando mais papéis inúteis nas prateleiras das bibliotecas.

Acho que cabe aos docentes auxiliar o aluno - desde o processo de seleção - a perceber da forma mais clara possível suas possibilidades concretas, até mesmo no que se refere à sua maturidade intelectual, para enfrentar uma determinada problemática do conhecimento histórico. Sem construir essa percepção também não há argumentos para os próprios orientadores estimularem projetos com bom prognóstico ou dissuadirem propostas que são inviáveis quer por sua temática, quer pelas possibilidades pessoais de um candidato. Nesse caso, sua realização acaba produzindo um tal conjunto de dificuldades, frustrações ou mesmo impossibilidades que o candidato abandona o curso, às vezes com profundos danos pessoais e em sua trajetória profissional. A realização de uma dissertação não pode se transformar em um desafio quase intransponível.

Acho que nós temos muito a ver com isso. Os docentes têm que assumir de forma mais efetiva e continuada o tipo de responsabilidade que decorre de orientar trabalhos com perfil impreciso como são as dissertações e cujos autores são alunos jovens, nem sempre capazes de perceber as implicações que suas propostas de pesquisa carregam, e o que talvez seja ainda mais difícil: que são historiadores em formação, com um longo aprendizado pela frente, que a dissertação não é o "alfa-ômega" de sua trajetória acadêmica e que modéstia e autocrítica não são qualidades menores nesse particular. A pós-graduação não é uma fábrica de dissertações e teses, mas um processo de formação de historiadores, que não é o mesmo que fazer uma dissertação.

De um pós-graduado em História espera-se autonomia profissional conquistada por meio do debate historiográfico e do domínio de instrumentos teórico-metodológicos e maturidade para exercer essa autonomia na elaboração e desenvolvimento de um projeto seja de uma dissertação ou tese. Entretanto insisto que o que

Anos 90, Porto Alegre, v. 13, n. 23/24, p.29-44, jan./dez. 2006 
nos deparamos freqüentemente é com a grande dificuldade que os estudantes têm para desenvolver esse percurso e com a falta de uma ação coletiva dos docentes para encaminhá-los nessa direção.

Por isso é fundamental que o Programa como um todo, e não apenas este ou aquele professor, fique atento para dificuldades que vão desde lacunas importantes na formação de graduação até falta de distanciamento crítico para, por exemplo, ponderar com realismo a vinculação existente entre o seu problema de pesquisa, a acessibilidade das fontes e sua própria bagagem de conhecimento sobre o que pretende pesquisar. Às vezes, sem que o estudante perceba, o tema envolve tantos desdobramentos, tantas questões paralelas, que se torna um "cipoal" impossível de ser desenredado no tempo em que dura uma pós-graduação. Isso deve ser bem avaliado para que não faça uma estimativa equivocada das dificuldades que vai enfrentar, o que ajudaria também que dissertações não resultassem em generalidades pouco significativas para o avanço de uma determinada temática. É certo que essas questões são sobretudo do âmbito da própria orientação que o aluno vai receber de um professor, mas na minha opinião o Programa como um todo deve estar preocupado em desenvolver permanentemente e em todas as atividades propostas esse tipo de postura coletiva e acadêmica voltada para ajudar o estudante a desenvolver uma reflexão crítica e sistemática sobre sua formação e produção científica, sem a qual, a meu ver, ele não desenvolverá a desejada autonomia e maturidade profissional.

Estamos sempre correndo, enfrentando cada vez mais exigências burocráticas, infindáveis formulários para preencher, relatórios sobre o mesmo que se superpõem, Programas nem sempre amistosos e cada vez com menos tempo para atender o que é o mais importante: os estudantes. Mas sem isso acho que ficamos lhes devendo uma experiência que possa se chamar, legitimamente, de pós-graduação. 
A Pós-Graduação em História...

Talvez essas questões sejam, de fato, muito difíceis de resolver, mas não são impossíveis. Na minha opinião, aqueles Programas que caminharem mais nesse sentido são os que farão a diferença para o futuro do conhecimento histórico no Brasil e para a qualidade e felicidade profissional dos novos historiadores.

E levando em conta nossa falta de tempo para falar e para ouvir, quis aproveitar esta oportunidade mais solene e simbólica dos 20 anos da Pós-Graduação em História da UFRGS para, pelo menos, refletir em público sobre essas questões.

Muito obrigada pela atenção!

Recebido em 02/08/2006.

Autora convidada. 